\title{
International Exchanges by College Nursing Students: "International Comparisons of Awareness and Challenges"
}

\author{
Yuko Harding \\ Faculty of Nursing, St. Mary's College, Fukuoka, Japan \\ Email: harding@stmaryacjp.onmicrosoft.com
}

How to cite this paper: Harding, Y. (2019) International Exchanges by College Nursing Students: "International Comparisons of Awareness and Challenges". Open Journal of Nursing, 9, 779-793.

https://doi.org/10.4236/ojn.2019.97059

Received: June 8, 2019

Accepted: July 27, 2019

Published: July 30, 2019

Copyright (อ 2019 by author(s) and Scientific Research Publishing Inc. This work is licensed under the Creative Commons Attribution-NonCommercial International License (CC BY-NC 4.0). http://creativecommons.org/licenses/by-nc/4.0/

\section{(c) (i) \& Open Access}

\begin{abstract}
Aim: The aim of this study was to determine the extent of awareness of international exchanges among college nursing students in Japan and other countries and to identify strategies to improve awareness. Method: This is an integrative literature review, consisting of scientific articles published on "Ichushi-Web," an Internet-based retrieval service by the Japan Medical Abstracts Society (JAMAS) and Google Scholar for domestic documents and, PubMed, Medline, Cochrane library and Google Scholar for foreign documents. Search parameters for "the years from 2000 to 2017" in combination with "international educational exchange", "schools, nursing", "students, nursing", "program evaluation", and "awareness" were employed. Result: The data were extracted from seven documents among a review of 29 retrieved domestic documents written in Japanese, and another seven documents among a review of 111 retrieved foreign documents written in English. All documents from Japan were reports of quantitative studies, and most documents from other countries were qualitative studies. The data from Japanese research reports were classified into four perspectives: interest in international exchange, need to participate in international exchange, understanding of different cultures and awareness of foreign settlers. The data from research reports from other countries were classified into three perspectives: understanding of different cultures, improving expertise in nursing, and awareness of the international community. Conclusions: Strategies that will enhance students' understanding of diverse cultures are needed to increase their awareness of international exchanges.
\end{abstract}

\section{Keywords}

International Educational Exchange, Schools, Nursing, Students, Nursing, Program Evaluation, Awareness 


\section{Introduction}

Japan's Ministry of Education, Culture, Sports, Science and Technology (2012) recommends that international exchanges occur as a way to cultivate human resources which can contribute to the international community in today's global society. Cultivation of human resources encompasses not only language ability, but also the imagination to create new values, and the ability to actively express one's ideas to the international community. However, in recent years, a decline in young students' and researchers' interest in foreign countries has become a social issue, as an "introspective view of young people" prevails [1].

At the end of 2013, the number of foreign residents in Japan was 2.38 million, and the number of permanent foreign residents rose to a record high of 727,000, an increase of 156,000 (6.7\%) from the end of the previous year. By nationality, China, South Korea and the Philippines make up 58.4 percent of the total number of foreign residents [2]. With the internationalization of Japan's population, opportunities for medical services for foreigners are increasing on a daily basis in medical and nursing clinics. In Japan, by promoting international exchange toward the internationalization of universities, it is required to break down the inward orientation of young people, which might be a reason for the lack of awareness, and to develop human resources that respond to a global society. Therefore, it is important to cultivate nursing students' understanding of diverse cultures, traditions, and customs, which can be accomplished by means of international exchanges.

\section{Definitions of the Terms}

According to Ministry of Foreign Affairs of Japan (2017), student exchange programs have the potential to further international friendship and mutual understandings, internationalize Japanese higher education institutions, revitalize industries and regions, and provide education for younger people of developing countries of the world. There is a global trend in demand for talented individuals who can take an active part in the ever globalizing world with valuable skills in foreign language and intercultural understanding [3]. Student interchange, through the hosting and sending of students, plays a significant role in promoting mutual understanding and building strong human networks between Japan and foreign countries. Such networks will become increasingly important in a globalized economy and society [4].

\section{Aim}

The aim of this study was to determine the extent of awareness of international exchanges among college nursing students in Japan and other countries and to identify strategies to improve their awareness.

\section{Method}

The review includes the result of observational (cross-sectional/longitudinal) stu- 
dies which explored the extent of awareness of international exchanges among college nursing students in Japan and other countries and to identify strategies to improve their awareness. Through September 2018, the following databases, "Ichushi-Web," the Internet-based retrieval service by Japan Medical Abstracts Society (JAMAS) [5], Google Scholar for domestic documents and PubMed, Medline, Cochrane library, Google Scholar for foreign documents were searched by the author to find additional studies related to the topic, as were the reference lists of included papers and related reviews. Search terms included a combination of keywords by thesaurus, i.e., "international educational exchange", "schools, nursing", "students, nursing", "program evaluation", and "awareness" and the retrieval year was "the whole year," and then original articles published were peer reviewed.

Articles were excluded if they were case reports, used research subjects who were not college nursing students, did not focus on the evaluation or awareness, or re-listing of duplicate documents. No further restrictions were made.

Based on the preferred responding items for systematic reviews (PRISMA 2009) [6], which also aim to improve the quality of systematic reviews, the search was performed in the next step. At first, records were identified through searching the database identified above. The author reviewed the titles of all retrieved articles; titles not meeting the predefined inclusion criteria were excluded. When the author was uncertain, or if the article was considered relevant, the author reviewed the abstracts and excluded records that did not meet the inclusion criteria. After an abstract review, when the author was uncertain regarding the relevance of an article or if the article was considered relevant, full texts were reviewed independently. Next, a search of Google Scholar and scanned titles of reviews identified in the first step, as well as the reference lists of selected papers and current relevant literatures, was performed (Figure 1).

In terms of analytical method, research trends focused on awareness of international exchange by college nursing students and current state and the issue concerning the extent of awareness of international exchange among college nursing students are described.

\section{Result}

\subsection{Research Trends Focused on Awareness of International Exchange by College Nursing Students}

The selection process of the object to be analyzed and containing search terms and pre-research fraction is shown in Figure 1. The data were extracted from seven documents among a review of 29 retrieved domestic documents (publication: 2004-2017) written in Japanese and another seven documents among a review of 111 retrieved foreign documents (publication: 2006-2017) written in English.

The literature review revealed that all data for Japanese articles were collected using surveys of mostly Japanese nursing students, with one study including Japanese and Korean students. In contrast, the content of articles from international sources was based primarily on reflections, with some data from interviews and 
Domestic documents

(international educational exchange $n=1,092$ )

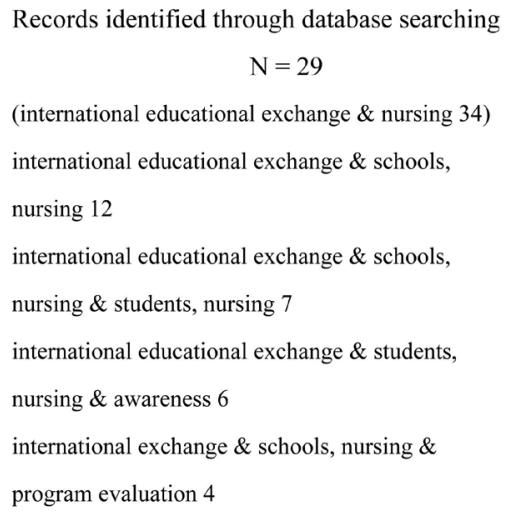

Records identified through database searching $\mathrm{N}=29$

(international educational exchange \& nursing 34)

international educational exchange \& schools,

nursing 12

international educational exchange \& schools,

nursing \& students, nursing 7

international educational exchange \& students,

nursing \& awareness 6

international exchange \& schools, nursing \&

program evaluation 4

Foreign documents

(international educational exchange $\mathrm{n}=3,332$ )

Records identified through database searching

$$
\mathrm{N}=111
$$

(international educational exchange \& nursing 743) international educational exchange $\&$ schools, nursing 77

international educational exchange \& schools, nursing \& students, nursing 14

international educational exchange \& students, nursing \& awareness 10

international exchange \& schools, nursing \&

program evaluation 10

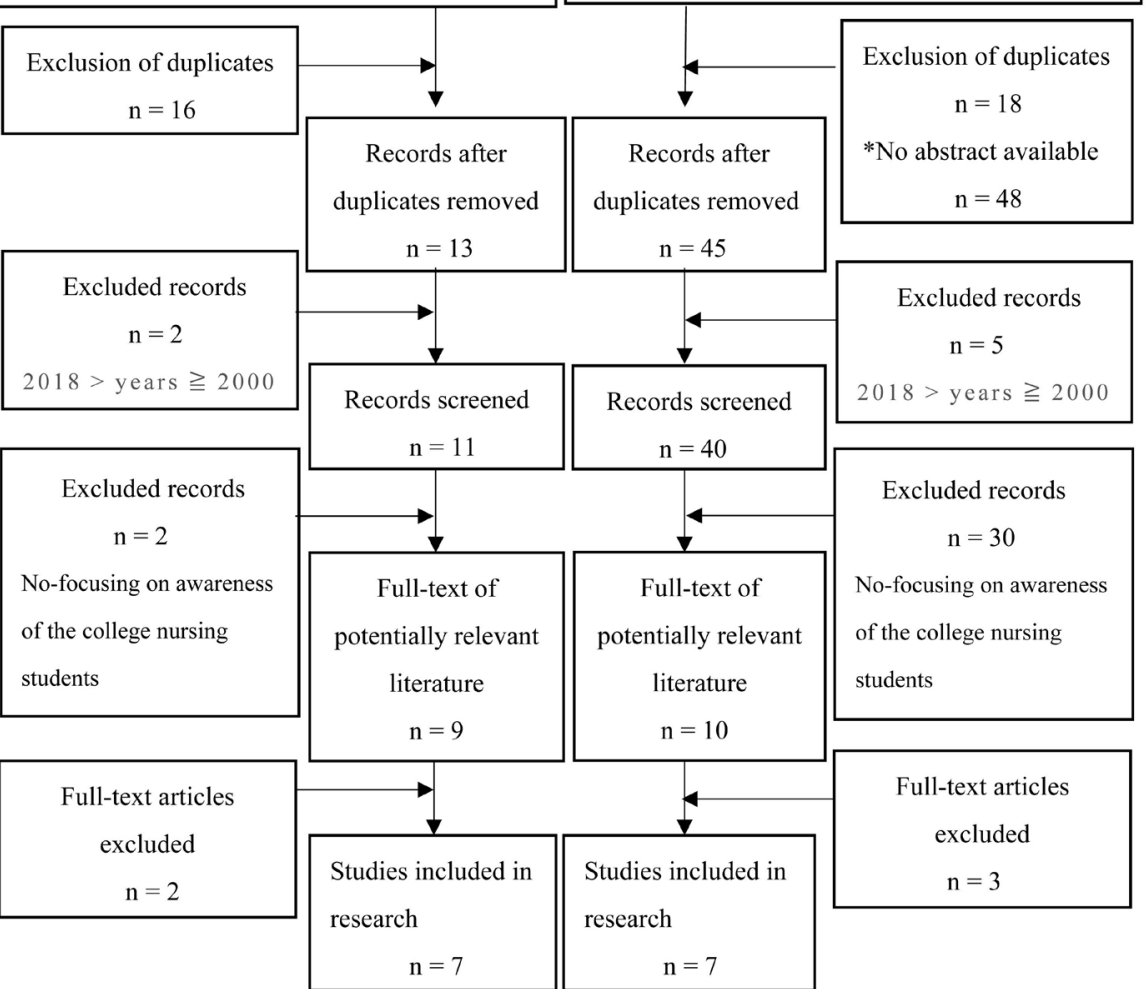

Figure 1. Flowchart of literature search and study selection.

one survey of nursing students and graduate students. Participants were Norway, Canada China, and the United States. The topic, purpose, study design, and participants reported in each article is shown in Table 1 (Japanese literature) and Table 2 (international literature).

\subsection{Current State Concerning the Awareness of International Exchange among College Nursing Students}

\subsubsection{In Domestic Literature; Study about Japanese College Nursing Students}

The data from Japanese research reports were classified into four perspectives: 
Table 1. Research trend: Literature in Japan.

\begin{tabular}{|c|c|c|}
\hline Topic & Purpose & Study design, Participants \\
\hline $\begin{array}{l}\text { Interest in } \\
\text { international }\end{array}$ & $\begin{array}{l}\text { Examining how nursing students' interest of international exchange and international } \\
\text { nursing change through overseas training procedure and their satisfaction for overseas } \\
\text { training (Yamaguchi et al. 2013) [8] }\end{array}$ & $\begin{array}{l}\text { Qualitative study, Questionnaire } \\
80 \text { nursing students }\end{array}$ \\
\hline \multirow{3}{*}{$\begin{array}{l}\text { Needs to } \\
\text { participate in } \\
\text { international } \\
\text { exchange }\end{array}$} & $\begin{array}{l}\text { Clarifying the needs for education concerning international exchange activities and nursing, } \\
\text { Understanding of the needs and awareness of international exchange, evaluation of where } \\
\text { international exchange activities are consistent with the needs and interests of students } \\
\text { (Nishito et al., 2014) [7] }\end{array}$ & $\begin{array}{l}\text { Qualitative \& Quantitative } \\
\text { Study, Questionnaire } \\
124 \text { nursing students }\end{array}$ \\
\hline & $\begin{array}{l}\text { Investigating what college students expected and participated in the overseas training } \\
\text { program and how they expected it (Kataoka., 2006) [9] }\end{array}$ & $\begin{array}{l}\text { Qualitative Study, Questionnaire } 8 \\
\text { nursing students }\end{array}$ \\
\hline & Nursing Students' Views on International Exchanges (Hamahata et al., 2004) [10] & $\begin{array}{l}\text { Quantitative study, Questionnaire, } \\
330 \text { nursing students }\end{array}$ \\
\hline $\begin{array}{l}\text { Understanding } \\
\text { of different } \\
\text { cultures }\end{array}$ & $\begin{array}{l}\text { Considering the educational effect of the experience of a nursing student exchange program } \\
\text { between Japan and Thailand (Ohue., 2016) [11] }\end{array}$ & $\begin{array}{l}\text { Qualitative study, Questionnaire } \\
\text { description questions, } 7 \text { nursing } \\
\text { students }\end{array}$ \\
\hline \multirow{2}{*}{$\begin{array}{l}\text { Awareness } \\
\text { of foreign } \\
\text { residents }\end{array}$} & $\begin{array}{l}\text { Examining associations between nursing students' knowledge and interest regarding foreign } \\
\text { nationals' medical health challenges and international exchange experience among Korean } \\
\text { and Japanese undergraduate nursing students (Ohnishi et al., 2017) [12] }\end{array}$ & $\begin{array}{l}\text { Quantitative study, Questionnaire } \\
68 \text { Japanese nursing students } \\
183 \text { Korean nursing students }\end{array}$ \\
\hline & $\begin{array}{l}\text { Examining the association between nursing students' knowledge and interest regarding } \\
\text { foreign resident medical health challenges and experience of international exchange as part } \\
\text { of an evaluation of global health educational programs (Nishihara et al., 2017) [13] }\end{array}$ & $\begin{array}{l}\text { Quantitative study } \\
\text { Questionnaire } \\
68 \text { nursing students }\end{array}$ \\
\hline
\end{tabular}

Table 2. Research trend: Literature abroad.

\begin{tabular}{|c|c|c|}
\hline Topic & Purpose & Study design, Participants \\
\hline \multirow{4}{*}{$\begin{array}{l}\text { Understanding of } \\
\text { different cultures }\end{array}$} & $\begin{array}{l}\text { Development of cultural competency at clinical placement in a } \\
\text { developing country (Ulvund et al., 2017) [14] }\end{array}$ & $\begin{array}{l}\text { Qualitative descriptive study, individual interviews } \\
18 \text { Norwegian nursing students }\end{array}$ \\
\hline & $\begin{array}{l}\text { International cultural immersion course in Guatemala, cultural } \\
\text { competence (Larson et al., 2010) [15] }\end{array}$ & $\begin{array}{l}\text { Qualitative descriptive study, } 7 \text { nursing students' } \\
\text { interview by the open-ended questions, and reflective } \\
\text { journals of all } 13 \text { American nursing students }\end{array}$ \\
\hline & $\begin{array}{l}\text { Fostering workplace cultural awareness through short-term global } \\
\text { experiences (Smith-Miller et al., 2010) [16] }\end{array}$ & $\begin{array}{l}\text { Qualitative study, reflection papers } \\
15 \text { American nursing students }\end{array}$ \\
\hline & $\begin{array}{l}\text { The immersion experience in partnership with IUB, Bangladesh } \\
\text { (Maltby et al., 2009) [17] }\end{array}$ & $\begin{array}{l}\text { Qualitative study, a descriptive phenomenological } \\
\text { design, a reflective journal } 17 \text { American nursing } \\
\text { students }\end{array}$ \\
\hline $\begin{array}{l}\text { Improving } \\
\text { expertise }\end{array}$ & $\begin{array}{l}\text { The development of health counseling skill and cultural awareness in } 15 \\
\text { institutes and/or universities, Taiwan, Macau, Chinese mainland and } \\
\text { Hong Kong (Lee et al., 2007) [18] }\end{array}$ & $\begin{array}{l}\text { Qualitative \& Quantitative study, Questionnaires. } \\
\text { group interviews, } 64 \text { nursing students in Taiwan, } \\
\text { Macau, Chinese mainland and Hong Kong }\end{array}$ \\
\hline in nursing & $\begin{array}{l}\text { Sustaining social consciousness with nursing students following } \\
\text { international learning experiences (Reimer et al., 2009) [19] }\end{array}$ & $\begin{array}{l}\text { Qualitative study, reports } \\
17 \text { Canadian nursing students }\end{array}$ \\
\hline $\begin{array}{l}\text { Awareness of } \\
\text { the international } \\
\text { community }\end{array}$ & $\begin{array}{l}\text { The personal and professional meaning of participating in international } \\
\text { clinical nursing electives (Callister et al., 2006) [20] }\end{array}$ & $\begin{array}{l}\text { Qualitative study, phenomenological analysis, } \\
\text { Audiotaped interview, } 15 \text { American nursing students } \\
\text { and } 5 \text { participants who had Master's degrees }\end{array}$ \\
\hline
\end{tabular}

interest in international exchange, need to participate in international exchange, understanding of different cultures and awareness of foreign residents.

\section{1) Interest in international exchange}


"The $84.7 \%(105 / 124)$ of the students had not participated in international exchange activities such as international exchange seminar, guidance for overseas medical students on visits to the school of nursing in their college. The reason was that $19 \%$ (20/105) of them were not interested." However, "The students interested in international exchange and nursing activities abroad was $70.2 \%$ (87/124), and $47.6 \%(59 / 124)$ wanted to participate in overseas training" [7]. "Students' motivation for attending overseas training was not enhanced after the preparation workshop. Their interest in international exchange and international nursing was enhanced after the preparation workshop but there was no statistically significant difference between the one after the preparation workshop and the one after overseas training" [8]. "Things that made the most significant impression on students after completing the training were the cultural differences, and exposure to the different cultures." On the other hand, "what students are concerned about in the training and the most troublesome for them during the training was language communication" [9]. As for language, "They felt more anxiety about English after the preparation workshop than before it" [8]. "The $6.5 \%(8 / 124)$ of students had regular opportunities to learn a foreign language [7].

\section{2) Needs to participate in international exchange}

In the experience of international exchange of college nursing students, “59.7\% (74/124) of nursing students have the experience of travelling overseas, and the purpose of the overseas travel experience was only to travel for $77 \%$ (54/74) of those nursing students who traveled. For travel destination, 50\% (37/74) of nursing students went to East Asia (China, Taiwan, Korea), and $43.2 \%$ (32/74) went to the US" [7]. Furthermore, according to another previous study, " $47.9 \%$ of 330 nursing students have experienced travel overseas in the past, as the purpose of the experience, travel accounted for 65\%. And the destinations were the US, 35\% and Asia, 32\%" [10].

The content of the desired training in international exchange among students is as follows. " $69.5 \%(41 / 59)$ of students visited local hospitals and medical facilities. $62.7 \%(37 / 59)$ of them were interacting with local people and students, and $61 \%(36 / 59)$ of them were giving lectures on nursing and medical care" [7]. "Prior to the start of the training, many students aimed primarily to deepen their knowledge and experience in line with their major, nursing, including visiting medical facilities" [9].

"In the future, $33 \%$ of the 330 students want to study abroad. Of the 111 students, the purposes of study abroad were $48 \%$ for language study, $31 \%$ for nursing professional study, $7 \%$ for nursing license, $4 \%$ for going to graduate school, and $10 \%$ for others." Also, "eighty-five percent of the students answered they would like to hear from the people of that country about the nursing situation overseas. Regions where students want to know the overseas nursing situation in particular were the United States $39 \%$, followed by Europe 34\%" [10].

3) Understanding of different cultures 
"Eighty-six percent of students answered that they had been able to deepen their understanding of different cultures through exchanges with Mahasarakham University in Thailand, and the contents of the understanding of different cultures were religious practice, differences in hygiene, supervision, gastronomic features/differences, smiling and hospitality culture, and culture of worship. Students learned features of medical care and nursing in Thailand, differences in nursing between Thailand and Japan in the medical system in Thailand during the facility tour, improvement of English ability, and learning how to present in English. They learned practical applications to nursing in Japan, and there is an educational effect which provides the nurses with an international viewpoint" [11].

\section{4) Awareness of foreign residents}

"A total of 65.6\% (120/183) of Korean students and 33.8\% (23/68) of Japanese students recognized the needs of healthcare for foreigners." "In addition, among the nursing students in both countries, the knowledge and interest in foreign health and medical care was significantly related to the richness of international exchange experiences (Whitney $\mathrm{U}$ test, $P=0.001, P=0.003$ )." "Among Japanese students, the abundance of international exchange experiences was significantly related to the awareness of the possibility of providing medical care for foreigners as future nurses (Mann-Whitney U test, $P=0.030$ " [12]. "Of all 68 nursing students, $23(33.8 \%)$ were aware of medical health challenges of foreign residents. There were significant differences in knowledge and interest scores regarding foreign residents' medical health challenges according to the international exchange experience $(P=0.003)$. The Spearman's rank correlation coefficient between level of interest regarding foreign residents' medical health challenges in Japan, as measured using a visual analog scale (VAS), and international exchange experience score, was $0.315(P=0.009)$ " [13].

\subsubsection{In Foreign Literature: Study about Foreign College Nursing Students}

The data from research reports from other countries were classified into three perspectives: understanding of different cultures, improving expertise in nursing, and awareness of the international community.

1) Understanding of different cultures

"Increased cultural awareness and a growing cultural competence was identified by Norwegian nursing students undertaking a four-week international clinical placement." [14] And "Through in-depth interviews and en vivo reflective journals of an international cultural immersion course in Guatemala, among American nursing students, the three themes: Navigating daily life (which was expressed as coping with hardship and practicing healthy behaviors), Broadening the lens (which described aspects of mothers and children's daily life), and Making a difference (for example, one student who taught dental hygiene was remarked on) revealed an expanded context and worldview of culture" [15]. Moreover, "Reflection papers written by baccalaureate or master's degree American nursing students, short-term Global experiences inform student nurses' 
cultural awareness, education, and future clinical practice. And it broadened their insight into multicultural care. The opportunity to reinforce language skills and cultural awareness can positively impact interaction with patients and mold future nursing practices. It could impact students' personal growth and professional competence" [16].

“Through American students' reflective journals after a three-week immersion experience in Bangladesh, students learned about people and healthcare through interviews and site visits.", "Four themes emerged from the data: Beginning to See, Thinking about the Seen, Wanting to Change the Seen, and Transformed by the Seen." [17]. "A two-week summer exchange program was conducted for nursing students in Taiwan, Macau, Chinese mainland and Hong Kong. From the result of questionnaires concerning evaluation of the program, they felt they had gained a greater awareness of effective health counselling skills and of cultural diversity in relation to their personal and professional development" [18].

\section{2) Improving expertise in nursing}

"Among Canadian nursing students who participated over twelve months following their international experiences, it was revealed that sustaining social consciousness over time is required to describe learning in international experiences, and to facilitate strategies that supported integration of this learning into personal and professional domains upon return to Canada" [19].

\section{3) Awareness of the international community}

"A new way of viewing the world was characterized by heightened social consciousness by international learning experience over twelve months" [19]. "For American former nursing students who participated in international nursing clinical experiences, there are broader implications for the movement beyond individual cultural competence to increasing global consciousness and the improvement of global health care" [20].

\subsection{The Issues Concerning the Awareness of International Exchange among College Nursing Students}

\subsubsection{In Domestic Literature}

1) Interest in international exchange

"Understanding trends of internationalization and how to provide nursing, promoting international exchange, and students who do not participate in overseas training are encouraged to engage in intra-college exchange with accepted foreign students" [7]. "It is also necessary to clarify and examine whether the content of preparatory learning prior to participation in overseas training has led to an increase in interest and motivation for learning in international affairs" [8]. "It is also necessary to have experiences of different cultures and to re-recognize the existence of others and oneself." [9] Regarding the study of languages, "The motivation for foreign language learning" [9] and "The promotion of language education from the early stages of lower grades" [7] are the challenges.

2) Participation needs in international exchange

It is written that the needs of "the overseas training programs focus on pro- 
viding support for students by college staff, preparing the college system and environment" [7], and "enhancing knowledge and experience about nursing and healthcare abroad" [9]. "It is necessary to provide the nursing situation overseas, to improve the educational environment for foreign language learning, to open international health and nursing courses, and to increase opportunities to invite foreign researchers" [10].

\section{3) Understanding of different cultures}

"It is necessary to broaden interests and views in international exchange, to provide support by college staff, and to organize the college's system and environment" [11].

\section{4) Attitudes toward foreign residents}

There were "the differences in sensitivity and recognition regarding medical healthcare provision for foreign nationals among Korean and Japanese nursing students. It is necessary to assess the factors responsible for this difference, to prepare nursing students for medical healthcare provision in the global society," and "to assess the influence of general society regarding globalization and to assess the details of formal nursing educational programs in the country." [12] Nursing educational institutions should develop solutions for international and global issues, including foreign residents' medical health challenges as essential knowledge and a sense of globalized medical health care provision among nursing students" [13].

\subsubsection{In Foreign Literature}

\section{1) Understanding of different cultures}

It is written, "investigate the best methods to support the students' reflection such that the experiences lead to learning" [14]. "Cultural immersion programs must be valued and embraced by nursing faculty in order to allow flexibility in nursing curricula and to support student participation" "More research is needed to explore and document the outcomes of cultural immersion programs and to establish curriculum guidelines for institutions nationwide" [15]. It is a challenge to "facilitate the development of student nurses' cultural competence and translate these experience into the clinical setting" [16]. "Achieving cultural competency is a complex, long-term process that can be intensified with immersion experiences through seeing through New Eyes" [17].

\section{2) Improving expertise in nursing}

"Educational institutions are strongly encouraged to provide opportunities for students to participate in exchange programs in order to broaden their perspective on nursing care and nursing education in other countries. The framework of integrating cultural components into exchange programs, with adequate preparation and clear insight on the cultural aspect, can provide students with many challenges and experiences." [18].

\section{3) Awareness of the international community}

"Considerable effort and intentionality was required to sustain social consciousness over time" [19] "Opening our hearts and minds which means in- 
creasing understanding of other cultures and people, global sociopolitical and health issues, making interpersonal connections, and developing cultural competence" [20] is important.

\section{Considerations}

\subsection{Research on Awareness of International Exchange among College Nursing Students}

From now on in Japan, a longitudinal study over the course of graduation will require evidence of the impact of participation in international exchange on the country after graduation. Research designs also draw attention to the phenomenological approach to qualitative research in reflective journal and interviewing methods, or to research by the Granted Theory Approach (GTA) as a position in the international community.

Because of that, most of the people surveyed were students from their own countries in domestic and foreign literature. From now on, it will be necessary to accumulate evidence of awareness assessment aimed at college students who are partners in international exchange implemented in Japan and abroad.

\subsection{Strategies to Improve College Nursing Students' Awareness of International Exchange (Figure 2)}

From each of the contents of current state and the issues concerning the awareness of international exchange among college nursing students, it can be suggested that college nursing students should support future challenges in the following six strategies for improving their awareness of international exchange in the future from.

\section{1) Interest in international exchange}

In order to promote international exchange, preparatory learning with consideration given to participating in training on the trend of internationalization and the manner of nursing in other countries is necessary, and it is important to examine and evaluate the content of the preparatory learning. A previous study by Leep et al. [21] concluded, "there is a need for nursing education to incorporate reflection into its curriculum," "Both students and faculty found that reflection, as a pedagogic tool, can be used effectively and meaningfully, as transitions to authenticity are forged."

As an incentive to learn a foreign language, it is necessary to establish an environment where students can develop the ability to actively appeal to themselves and their own countries by using foreign languages voluntarily, mainly in communication classes with foreign teachers. In order to achieve this, it will be necessary to review the curriculum in colleges, such as the promotion of language education from the early stages of the lower grades and the increase in the number of units of English for nursing care. Acquisition of technical terms in the field of nursing science in other languages is also essential for understanding and raising awareness about nursing in other countries. 


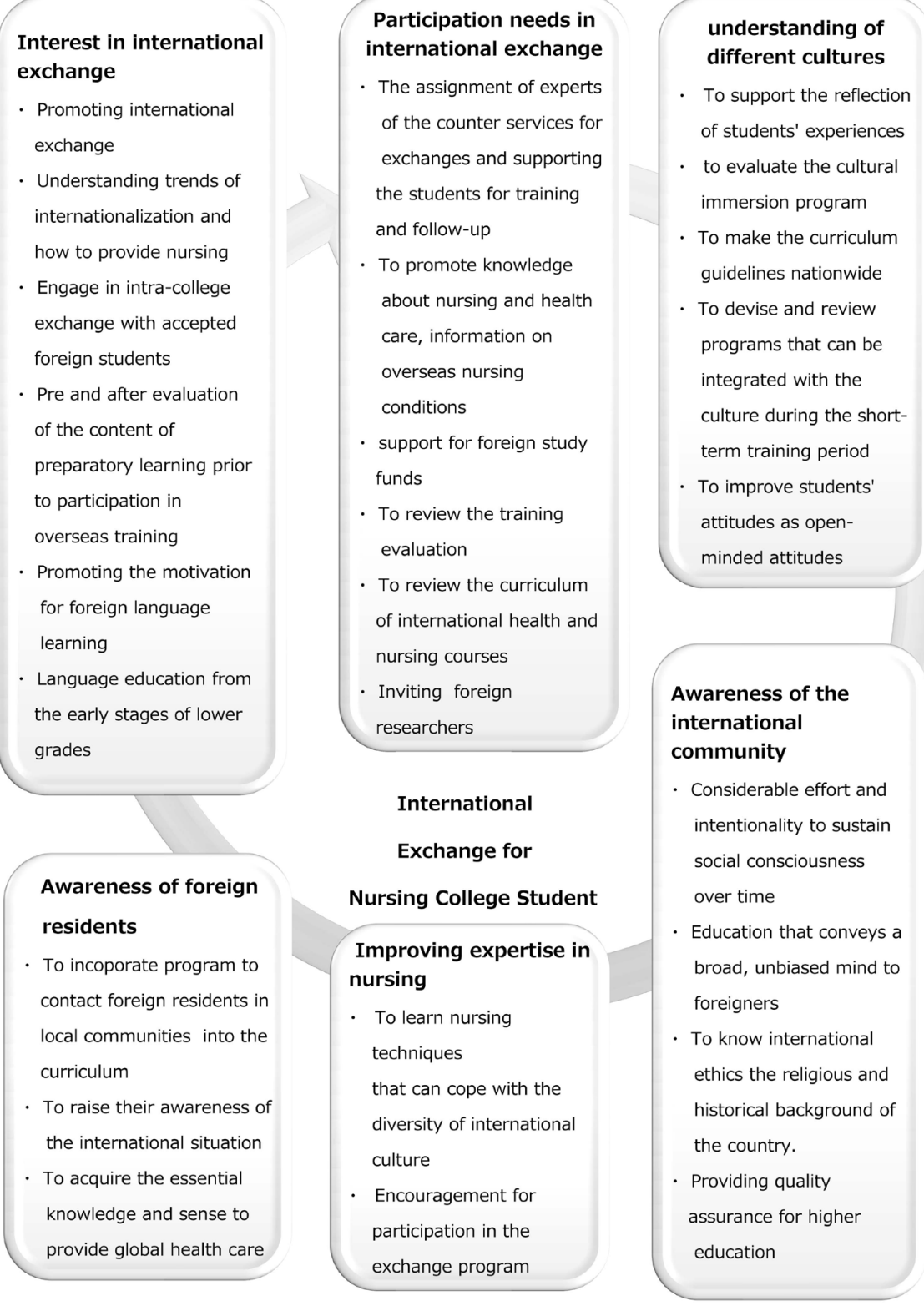

Figure 2. Strategies to improve college nursing students' awareness of international exchange.

\section{2) Participation needs in international exchange}

In overseas training, the assignment of experts in charge of international exchange as well as college faculty members is essential in order to increase the requirement for students to participate. The person in charge is an important person in charge of the counter services for exchanges with overseas affiliated universities, supporting the students in attendance in preparation for training and follow-up, cooperating with teachers, and developing the university system and environment.

The role of the International Exchange Commission established in colleges is to promote students' knowledge about nursing and health care, and to promote 
information on overseas nursing conditions and support for foreign study funds by publishing it in the press (institutional papers and the web) and publicizing it. In response to reports from leading teachers during training abroad and reports by working groups of colleges when foreign students are accepted from schools affiliated with colleges abroad, it will be necessary to review the training evaluation by members of the International Exchange Commission and grasp the participation needs, including foreign students from other countries.

At the college level, it is necessary to evaluate international exchange among nursing students, review the curriculum of international health and nursing courses, increase opportunities for foreign researchers to be invited, and implement overseas study fairs. At the national level, it is also necessary to establish certain budgetary allocations for international exchange activities, economic assistance such as support money for study abroad and scholarships, and criteria for international exchange evaluation for each educational institution.

\section{3) Understanding of different cultures}

In order to gain an understanding of different cultures, it is necessary to provide support that enhances the reflection of students' experiences with a fluidic relationship and helps them to promote the development of their cultural abilities by their own efforts. The cultural immersion program needs to be evaluated in order to allow clinical return of overseas experiences.

In order to deepen students' understanding of different cultures, it is necessary to make the curriculum guidelines nationwide and to devise and review programs that can be integrated with the culture during the short-term training period. One research finding by Greatrex-White (2007) show, "study abroad afforded the participating students the opportunity to develop an awareness not only of the host culture but importantly an awareness of their own culture and the deeply embedded structures and practices that impact their own being in the world and that of others" [22]. As an international competence by Bryam (1997) [23], it is necessary to improve students' attitudes as open-minded attitudes, knowledge about not only other countries but also their own customs, and the skills to discover and interact them.

\section{4) Attitudes toward foreign residents}

In order to raise awareness of medical care for foreign residents, programs that contact foreign residents in local communities need to be incorporated into the curriculum in Japan, too. In addition, if the students have a high level of language ability, they will be able to raise their awareness of the international situation and acquire the essential knowledge and sense to provide global health care, which will make them more aware of foreign residents. Hence, they will be able to respond to foreigners in clinical settings, and will become business-ready.

\section{5) Improvement of expertise}

It is necessary to learn nursing techniques that can cope with the diversity of international culture. Encouragement is required for participation in the exchange program, and learning local nursing knowledge and skills in overseas 
training can lead to a review of specialized skills in one's own country. If possible, it is appropriate for students who have completed learning the basic skills of nursing to be able to compare with their own country's technology and exchange opinions at the place where they are conducting overseas training.

\section{6) Awareness of the international community}

Considerable effort and intentionality to sustain social consciousness over time require the flexibility of thinking to incorporate diverse opinions. A previous study by Reimer-Kirkham et al. [24] reveals "The historical, social and cultural aboriginal context prompted increased student learning of social justice." Education that conveys a broad, unbiased mind to foreigners also needs to know international ethics and the religious and historical background of the country. Japan's per capita GDP (Gross domestic product) has fallen sharply since 2000 as the working-age population decreased due to the rapidly declining birth rate. We need people who can play a global role in revitalizing Japan's economy and maintaining its vitality. Providing quality assurance for higher education is also required in nursing college education.

\section{Summary}

The extent of awareness of international exchanges among college nursing students in Japan and other countries, and the strategies to improve their awareness in the future, were clarified through the comparison of literature in Japan and abroad. Six strategies were identified: interest in international exchange, need to participate in international exchange, understanding of different cultures, awareness of foreign residents, improving expertise in nursing, and awareness of the international community.

\section{Funding}

This research did not receive any specific grant from funding agencies in the public, commercial, or not-for-profit sectors.

\section{Conflicts of Interest}

The author declares no conflicts of interest regarding the publication of this paper.

\section{References}

[1] Annual Report on Ministry of Education, Culture, Sports, Science and Technology Japan, Chapter 8 Enhancement of International Exchange-Cooperation. http://www.mext.go.jp/b_menu/hakusho/html/hpab201201/detail/1324676.htm

[2] Immigration Bureau of the Ministry of Justice (2017) The Number of Foreign Residents at of the End of 2016 (Definite Value). http://www.moj.go.jp/nyuukokukanri/kouhou/nyuukokukanri04_00065.html

[3] Ministry of Foreign Affairs of Japan (2017) People-to-People Exchange, Student Exchange Program.

https://www.mofa.go.jp/policy/culture/people/student/index.html 
[4] Student Services Division, Higher Education Bureau Ministry of Education, Culture, Sports, Science and Technology, Japan (2006) Outline of the Student Exchange System in Japan.

http://www.mext.go.jp/a_menu/koutou/ryugaku/06082503/002.pdf

[5] JAMAS (2019) https://www.jamas.or.jp/english/

[6] PRISMA (2015) http://www.prisma-statement.org/

[7] Nishito, T., Tsukinoki, R., Cardenas, X., Kobayashi, M. and Kobayashi, T. (2014) Nursing Students' Views on International Exchanges in the Nursing Education. Osaka Medical College Journal of Nursing Research, 4, 96-104.

https://ci.nii.ac.jp/naid/40020043895/en/?range=0\&sortorder=1\&start=1\&count=20

[8] Yamaguchi, Y. and Teraoka, T. (2013) Education of International Nursing through Overseas Training: Changing of Interest for Studies and Satisfaction of Overseas Training. Journal of Academy of Nursing Education Research, 5, 42-48.

https://ci.nii.ac.jp/naid/40019955982/en/?range=0\&sortorder=1\&start=1\&count=20 \&q=\&nrid=9000237776227

[9] Kataoka, Y. (2006) Aichi Prefectural College of Nursing \& Health Study Abroad Tour in the US, Spring 2006: A Report. Aichi Prefectural College of Nursing \& Health, 12, 59-66. https://ci.nii.ac.jp/naid/110006282305

[10] Hamahata, A., Kataoka, Y., Yoneda, M., Hirai, S., Furuta, K., Harasawa, Y. and Hoshino, J. (2004) Nursing Students' Views on International Exchanges. Aichi Prefectural College of Nursing \& Health, 10, 27-32. https://ci.nii.ac.jp/naid/110006275639

[11] Ohue, T. (2016) Educational Effect of a Nursing Student International Exchange with the Faculty of Nursing at Mahasarakham University, Thailand. Hyogo University Journal, 21, 25-34.

https://iss.ndl.go.jp/books/R000000004-I028865089-00?locale=en\&ar=4e1f

[12] Ohnishi, M., Tanaka, J., Nishihara, M., Lee, J.Y., GO, H.N. and Morifuji, K. (2017) A Study on Undergraduate Nursing Students' Perspective of Healthcare Provision for Foreign Nationals: A Survey on Japanese and Korean University Students. Health Science Research, 30, 1-10.

http://naosite.lb.nagasaki-u.ac.jp/dspace/bitstream/10069/37708/1/hokenn30_1.pdf

[13] Nishihara, M., Tanaka, J., Manago, Y., Sakata, K., Kubo, N. and Ohnishi, M. (2017) Japanese Undergraduate Nursing Students with International Exchange Experience Anticipate a Probability of Providing Care to Foreign Nationals as a Nurse. Health Science Research, 29, 73-80. http://naosite.lb.nagasaki-u.ac.jp/dspace/bitstream/10069/37037/1/hokenn29_73.pdf

[14] Ulvund, I. and Mordal, E. (2017) The Impact of Short Term Clinical Placement in a Developing Country on Nursing Students: A Qualitative Descriptive Study. Nurse Education Today, 55, 96-100. https://doi.org/10.1016/j.nedt.2017.05.013

[15] Larson, K.L., Ott, M. and Miles, J.M. (2010) International Cultural Immersion: En Vivo Reflection in Cultural Competence. Journal of Cultural Diversity, 17, 44-50. https://www.ncbi.nlm.nih.gov/pubmed/20586365

[16] Smith-Miller, C.A., Leak, A., Harlan, C.A., et al. (2010) "Leaving the Comfort of the Familiar": Fostering Workplace Cultural Awareness through Short-Term Global Experiences. Nursing Forum, 45, 18-28. https://doi.org/10.1111/j.1744-6198.2009.00163.x

[17] Maltby, H.J. and Abrams, S. (2009) Seeing with New Eyes: The Meaning of an Immersion Experience in Bangladesh for Undergraduate Senior Nursing Students. International Journal of Nursing Education Scholarship, 6, 1-15. https://doi.org/10.2202/1548-923X.1858 
[18] Lee, R.L., Pang, S.M., Wong, T.K. and Chan, M.F. (2007) Evaluation of an Innovative Nursing Exchange Program: Health Counseling Skills and Cultural Awareness. Nurse Education Today, 27, 868-877. https://doi.org/10.1016/j.nedt.2006.12.002

[19] Reimer Kirkham, S., Van Hofwegen, L. and Pankratz, D. (2009) Keeping the Vision: Sustaining Social Consciousness with Nursing Students Following International Learning Experiences. International Journal of Nursing Education Scholarship, 6, 1-16. https://doi.org/10.2202/1548-923X.1635

[20] Callister, L.C. and Cox, A.H. (2006) Opening Our Hearts and Minds: The Meaning of International Clinical Nursing Electives in the Personal and Professional Lives of Nurses. Nursing \& Health Sciences, 8, 95-102. https://doi.org/10.1111/j.1442-2018.2006.00259.x

[21] Leep, M., Zorn, C.R., Duffy, P.R. and Dickson, R.J. (2003) International Education and Reflection: Transition of Swedish and American Nursing Students to Authenticity. Journal of Professional Nursing, 19, 164-172. https://doi.org/10.1016/S8755-7223(03)00066-8

[22] Greatrex-White, S. (2008) Uncovering Study Abroad: Foreignness and Its Relevance to Nurse Education and Cultural Competence. Nurse Education Today, 28, 530-538. https://doi.org/10.1016/j.nedt.2007.09.005

[23] Bryam, M. (1997) Teaching and Assessing Intercultural Communicative Competence. Multingual Matters Ltd., Clevedon, 31-55.

[24] Reimer Kirkham, S., Hoe Harwood, C. and Van Hofwegen, L. (2005) Capturing a Vision for Nursing: Nursing Students in Alternative Clinical Settings. Nurse Educator, 30, 263-270. https://doi.org/10.1097/00006223-200511000-00012 